\title{
Mutational and transcriptional analysis of the Campylobacter jejuni flagellar biosynthesis gene flhB
}

\author{
Claudia Matz, ${ }^{1} \dagger$ Arnoud H. M. van Vliet, ${ }^{2,3}$ Julian M. Ketley ${ }^{3}$ \\ and Charles W. Penn ${ }^{1}$
}

Author for correspondence: Charles W. Penn. Tel: +44 21 146562. Fax: +44 121145925. e-mail:c.w.penn@bham.ac.uk

1 School of Biosciences, University of Birmingham, Edgbaston, Birmingham B15 2TT, UK

2 Department of Gastroenterology and Hepatology, Academic Hospital Dijkzigt, Dr Molewaterplein 40, 3015 GD Rotterdam, The Netherlands

3 Department of Genetics, University of Leicester University Road, Leicester LE1 7RH, UK

\begin{abstract}
A Campylobacter jejuni gene encoding a homologue of the flagellar biosynthesis gene $\mathrm{flhB}$ was identified downstream of the peroxide stress defence gene ahpC. Insertional mutagenesis of the $f \mathbf{h B}$ gene rendered $C$. jejuni non-motile, with most cells aflagellate, although a small number expressed truncated flagella. The absence of FlhB also appeared to affect cell shape, as the majority of cells were straight rather than curved rods. Transcription of the flagellin gene flaA was significantly reduced in the $C$. jejuni flhB mutants, which also did not express significant amounts of flagellin proteins, indicating that FlhB is an essential protein for subsequent expression of flagellar genes. The transcription start site of the flhB gene, as determined by primer extension, was located 91 bp upstream of the flhB start codon, but no recognizable promoter sequence could be identified immediately upstream of this transcription start site. Transcriptional fIhB: : lacZ reporter gene fusions confirmed that the fIhB gene has its own promoter region, is expressed at very low levels and is transcribed independently of ahpC, and that its transcription is not regulated by iron or growth phase.
\end{abstract}

Keywords: Campylobacter, motility, transcription

\section{INTRODUCTION}

The human pathogen Campylobacter jejuni is recognized as one of the major causes of bacterial gastroenteritis, and is considered to be an important public health and economic burden (van Vliet \& Ketley, 2001). The high level of motility conferred by flagella, together with the spiral, curved shape, allow C. jejuni to penetrate the mucus layer overlying the intestinal epithelium (Szymanski et al., 1995). Flagella and motility have also been implicated in adhesion and invasion of $C$. jejuni (Wassenaar et al., 1991), and are required for intestinal colonization in chicken colonization models (Nachamkin et al., 1993; Wassenaar et al., 1993).

The determination of the complete genome sequence of C. jejuni has allowed the identification of putative flagellar genes in C. jejuni (Parkhill et al., 2000). Comparison with flagellar genes of the Enterobac-

†Present address: School of Pharmaceutical Sciences, University of Nottingham, Nottingham NG7 2RD, UK. teriaceae indicated that regulation and biosynthesis of flagella in C. jejuni is likely to be different from that of the Enterobacteriaceae (Chilcott \& Hughes, 2000; Macnab, 1996; Parkhill et al., 2000), more closely resembling the organization predicted for the related pathogen Helicobacter pylori (O'Toole et al., 2000; Tomb et al., 1997). C. jejuni contains the flagellar sigma factors $\sigma^{28}$ and $\sigma^{54}$ (Jagannathan et al., 2001; Wösten et al., 1998a) and a homologue of the H. pylori flgR gene, which encodes a $\sigma^{54}$-associated activator of transcription of the flagellar hook, basal body and FlaB flagellar filament genes (Jagannathan et al., 2001; Spohn \& Scarlato, 1999).

So far, relatively few C. jejuni genes involved in flagellar biosynthesis have been investigated. In recent studies using random transposon mutagenesis or site-directed mutagenesis, it was demonstrated that mutations in at least 19 genes led to altered or absent motility of C. jejuni (Colegio et al., 2001; Hendrixson et al., 2001; Jagannathan et al., 2001). One of these C. jejuni genes is flhB (Hendrixson et al., 2001), which encodes a protein that in Salmonella enterica serovar Typhimurium is 


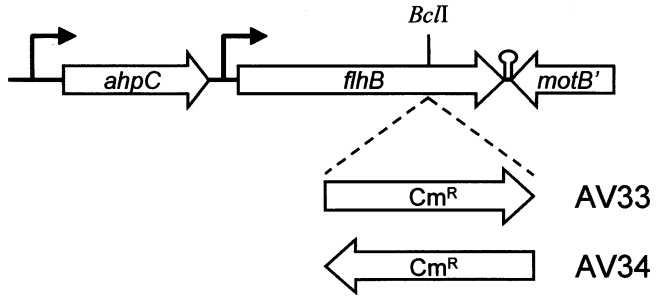

Fig. 1. Schematic diagram representing the genomic region containing the $f / h B$ gene. The position and orientation of the cat cassette inserted into the $B C / l$ site of $f / h B$ and the resulting mutants are shown. Promoters of $f l h B$ and $a h p C$ are indicated by arrows, and a putative terminator structure is indicated by a stem-loop symbol.

involved in the flagellar protein export pathway, and in the hook-length-dependent switch in export specificity from basal-body-hook proteins to filament and associated proteins (Kutsukake et al., 1994; Kutsukake, 1997; Minamino et al., 1994; Minamino \& Macnab, 1999, 2000; Williams et al., 1996). As in C. jejuni, mutation of flhB in $H$. pylori resulted in a non-motile phenotype (Foynes et al., 1999). Synthesis of the flagellar filament proteins FlaA and FlaB, and the hook protein FlgE, was almost completely abolished in the $H$. pylori flbB mutant, and transcription of the fla $A, f l a B$ and $f l g E$ genes was significantly reduced (Allan et al., 2000).

Examination of the nucleotide sequence downstream of the peroxide stress defence gene $a b p C$ (Baillon et al., 1999) revealed the presence of the motility-associated genes $f h B$ and $\operatorname{mot} B$ (Fig. 1). In this study, we have characterized the transcriptional organization and regulation of $f l h B$, and show that mutation of $f l h B$ affects C. jejuni motility and flagellin expression.

\section{METHODS}

Bacterial strains and growth conditions. The C. jejuni strains used in this study are 81116 (NCTC 11828), 480 (NCTC 12744) (National Collection of Type Cultures) and the $C$. jejuni 81116 flagellar mutants R2 $\left(\mathrm{FlaA}^{-} \mathrm{FlaB}^{-}\right)$, R3 (FlaA ${ }^{+}$ $\mathrm{FlaB}^{-}$) and $\mathrm{R} 4$ (FlaA ${ }^{-} \mathrm{FlaB}^{+}$) (Wassenaar et al., 1991). C. jejuni strains were cultured in Mueller-Hinton (MH) media (Oxoid) at $37^{\circ} \mathrm{C}$ under microaerobic conditions $\left(5 \% \mathrm{O}_{2}, 5 \% \mathrm{CO}_{2}\right.$, $90 \% \mathrm{~N}_{2}$ ). Antibiotics were used at the following final concentrations : $10 \mu \mathrm{g}$ vancomycin $\mathrm{ml}^{-1}, 50 \mu \mathrm{g}$ kanamycin $\mathrm{ml}^{-1}$, and $20 \mu \mathrm{g}$ chloramphenicol $\mathrm{ml}^{-1}$, when appropriate. Ironrestricted growth conditions were achieved by supplementing MH medium with Desferal (Sigma) to a final concentration of $20 \mu \mathrm{M}$ (van Vliet et al., 1998b). For motility tests, C. jejuni grown overnight in $\mathrm{MH}$ broth at $37^{\circ} \mathrm{C}$ under microaerobic conditions was diluted in $\mathrm{MH}$ broth to approximately 100 cells $\mathrm{ml}^{-1}$, and, subsequently, $100 \mu \mathrm{l}$ of this cell suspension was added to $5 \mathrm{ml}$ soft agar [ $\mathrm{MH}$ broth containing $0.3 \%$ (w/v) agar, cooled to $45^{\circ} \mathrm{C}$ ], poured onto soft agar plates $[\mathrm{MH}$ broth containing $0.4 \%(\mathrm{w} / \mathrm{v})$ agar], and incubated for 2 days microaerobically at $37^{\circ} \mathrm{C}$.

Recombinant DNA techniques. Plasmid preparations, restriction endonuclease digestions, ligations and transformations of
Escherichia coli were performed according to standard procedures (Sambrook et al., 1989). All restriction and modifying enzymes were purchased from Gibco-BRL and used according to the manufacturer's instructions. Genomic DNA was isolated by the IsoQuick nucleic acid extraction kit (ORCA Research). A PCR was performed using Vent polymerase (New England Biolabs) or Taq polymerase (Life Technology) according to the manufacturer's instructions. Allelic exchange mutagenesis of $f l h B$ was performed by insertion of the chloramphenicol-resistance (cat) cassette of plasmid pAV35 (van Vliet et al., 1998b) in both transcriptional orientations into the unique $B c l$ I restriction site of the $f h B$ gene (Fig. 1). The resulting plasmids, pAV107 and pAV108, were introduced into C. jejuni 81116 using electroporation (van Vliet et al., 1998a), and yielded C. jejuni strains AV33 and AV34 $\left(f l h B:: \mathrm{Cm}^{\mathrm{R}}\right.$ ) (Fig. 1). Correct replacement of the wild-type $f l b B$ gene by the $f l b B:: c a t$ gene was verified by Southern blotting (not shown).

RNA isolation and analysis. Total RNA was isolated from $C$. jejuni overnight cultures as described previously (Oelmuller $e t$ al., 1990). Primer extension was performed using primers PE1 and PE2 (5'-CTATCTTTTTGGACGTGGGTTC-3' and 5'-CTGCCGCATCTTGAGACTTTGG-3') essentially as described previously (Baillon et al., 1999). For Northern hybridization, RNA was transferred, using standard protocols (Sambrook et al., 1989), to Amersham Hybond- $\mathrm{N}^{+}$nylon membranes and hybridized with PCR-amplified flaA- and $f l b B$-specific probes. The flaA and $f l b B$ probes consisted of parts of the flaA gene (positions 1269232-1270532 on the C. jejuni genome; Parkhill et al., 2000) and the $f l b B$ gene (positions 303149-304169 on the C. jejuni genome; Parkhill et al., 2000), respectively. All probes were labelled with $\left[\alpha^{32} \mathrm{P}\right] \mathrm{dATP}$ by using the Radprime DNA labelling kit and random hexanucleotide primers (Life Technology).

Reporter gene assays. The C. jejuni promoter probe vector pMW10 contains a promoterless lac Z gene, and has previously been used to quantify promoter activity in C. jejuni (Baillon et al., 1999; van Vliet et al., 2000; Wösten et al., 1998b). Overlapping fragments containing the $f h B$ start codon and various parts of the upstream region were amplified by PCR, checked for the absence of PCR incorporation errors by DNA sequencing, and subsequently cloned into the BamHI site of pMW10 (Table 1). As positive controls, the C. jejuni 81116 ahpC (Baillon et al., 1999) and flaA promoters were used (Table 1). The constructs were transformed into C. jejuni strain 480, and $\beta$-galactosidase activity was measured as described previously (Baillon et al., 1999; van Vliet et al., 2000; Wösten et al., 1998b), after approximately 7.5 h growth, at an $\mathrm{OD}_{600}$ of approximately $0 \cdot 4$. The $\beta$-galactosidase activities were expressed in Miller units (Sambrook et al., 1989) and were derived from three independent experiments.

Protein analysis. C. jejuni wild-type and $f l h B$ mutants were grown on $\mathrm{MH}$ agar for $24 \mathrm{~h}$, fractionated into periplasmic, cytoplasmic and membrane-bound proteins (van Vliet et al., 1998b) and subjected to SDS-PAGE (Sambrook et al., 1989). Gels were either stained with PAGE blue 83 (Fluka) or immunoblotted and subsequently incubated with mouse monoclonal antibodies $\mathrm{P} 3 \mathrm{~B} 2$ and $\mathrm{O} 2 \mathrm{D} 4$, which recognize both Campylobacter flagellin A and flagellin B (Constantinidou et al., 1996; Jagannathan et al., 2001).

Electron microscopy. C. jejuni wild-type and $f h B$ mutants were grown on $\mathrm{MH}$ agar for $24 \mathrm{~h}$, negatively stained in $1.25 \%$ $(\mathrm{w} / \mathrm{v})$ sodium phosphotungstate $(\mathrm{pH} 7 \cdot 0)$, and examined with a Jeol JEM1200EX transmission electron microscope. 
Table 1. Promoter activity of flhB promoter-lacZ fusions

\begin{tabular}{|c|c|c|c|c|}
\hline \multirow[t]{2}{*}{ Clone } & \multirow[t]{2}{*}{ lacZ fusion to: } & \multirow[t]{2}{*}{ Position* } & \multicolumn{2}{|c|}{$\beta$-Galactosidase activity $\dagger$ after growth in: } \\
\hline & & & $\begin{array}{l}\text { Iron-replete } \\
\text { medium } \neq\end{array}$ & $\begin{array}{l}\text { Iron-restricted } \\
\text { medium } \neq\end{array}$ \\
\hline pCM1 & Promoter $f l h B$ with complete $a h p C$ gene and promoter & $302160-303147$ & $6 \cdot 1 \pm 0 \cdot 5$ & $8 \cdot 6 \pm 0 \cdot 2$ \\
\hline pCM2 & Promoter $f l b B$, with large part of $a h p C$ gene & $302421-303147$ & $11 \cdot 9 \pm 1 \cdot 1$ & $11 \cdot 5 \pm 0 \cdot 6$ \\
\hline pCM3 & Promoter $f l h B(-75$ to +140$) \mathbb{S}$ & $302933-303147$ & $12 \cdot 0 \pm 1 \cdot 2$ & $10 \cdot 6 \pm 1 \cdot 1$ \\
\hline pCM4 & Promoter $f l h B(+5$ to +140$) \mathbb{S}$ & $303012-303147$ & $1 \cdot 7 \pm 0.5$ & $2 \cdot 0 \pm 0 \cdot 6$ \\
\hline pMW10 & None & - & $1 \cdot 8 \pm 0 \cdot 5$ & $1 \cdot 9 \pm 0 \cdot 2$ \\
\hline pAV197 & Promoter region $a h p C$ & $302157-302402$ & $367 \cdot 6 \pm 34 \cdot 0$ & $973 \cdot 4 \pm 49 \cdot 7$ \\
\hline pAV150 & Promoter flaA & $124-508 \|$ & $269 \cdot 2 \pm 19 \cdot 1$ & $249 \cdot 7 \pm 22 \cdot 3$ \\
\hline
\end{tabular}

*Position of the DNA fragment in the C. jejuni genome sequence (Parkhill et al., 2000).

$\dagger \beta$-Galactosidase activity (in Miller Units, $\pm \mathrm{SD}$ ) after 7.5 h growth. Results shown are derived from three independent experiments. $\ddagger$ Iron-replete medium consisted of $\mathrm{MH}$ broth; iron-restriction was achieved by supplementation of $\mathrm{MH}$ broth with $20 \mu \mathrm{M}$ Desferal. $\mathbb{S R e l a t i v e}$ to experimentally determined transcription start site.

|| Position in the C. jejuni 81116 promoter sequence (GenBank accession no. AF202168) (Nuijten et al., 2000).

\section{RESULTS}

\section{Identification and mutation of a C. jejuni flhB homologue}

Examination of the sequence downstream of the $C$ jejuni 81116 ahpC oxidative stress defence gene had previously revealed the presence of a gene encoding an FlhB homologue (Baillon et al., 1999). The predicted C. jejuni FlhB protein is $37 \%$ identical, and $56 \%$ similar, to the FlhB protein of $H$. pylori and shows strong conservation of hydrophobic and hydrophilic domains when compared with the FlhB protein of S. enterica serovar Typhimurium (not shown).

The $f l h B$ gene of C. jejuni strain 81116 was mutated by insertion of a cat cassette in both transcriptional orientations into the unique $B c l$ I restriction site of $f l h B$ (Fig. 1), followed by allelic replacement of the wild-type $f l h B$ gene with the interrupted gene. This resulted in the isolation of C. jejuni strains AV33 and AV34 (81116 $f l h B:: \mathrm{Cm}^{\mathrm{R}}$ ) (Fig. 1). Correct replacement of the wildtype $f h B$ gene with its interrupted counterpart was confirmed by Southern blot analysis (data not shown). Mutants AV33 and AV34, which had the cat cassette in opposite orientations, gave identical flagellar phenotypes in all tests (not shown). This indicates there was no polar effect on flagellar gene expression from the insertion of the cat cassette.

\section{Mutation of flhB affects C. jejuni motility and cell shape}

The relative motility of $f l h B$ mutants was compared with that of C.jejuni 81116 wild-type and the aflagellate, non-motile mutant R2 (FlaA ${ }^{-} \mathrm{FlaB}^{-}$) (Wassenaar et al., 1991). C. jejuni 81116 had spread to the edge of soft-agar plates after 3 days incubation, whilst the R2 mutant had produced small, distinct colonies. Like the R2 mutant, the $f l b B$ mutants were non-motile, although the colonies were slightly larger than those of R2 (data not shown). Electron microscopy of the C. jejuni flhB mutants (Fig. 2) showed that the $f h B$ mutants lacked flagella and often lost the spirally curved morphology typical of wild-type C. jejuni 81116. Occasionally, cells with truncated flagella and a spirally curved morphology were observed among $f h B$ mutants (Fig. 2b), but we were unable to identify these as colonies showing motility on motility plates and hence could not characterize them further (data not shown).

\section{Mutation of flhB affects flagellin expression and transcription}

Expression of the flagellar proteins FlaA and FlaB was absent in the $f l h B$ mutants, as assessed using monoclonal antibodies (Fig. 3a). This indicates that the non-motile phenotype of the $f l h B$ mutants is caused, at least in part, by blocked expression of flagellin protein. Repression of flagellin expression appeared to be mediated at the transcriptional level, since flagellin mRNA levels were significantly reduced in the $f h B$ mutants (Fig. $3 b$ ), though not absent as in the flagellar mutants R2 and R4 (Fig. 3b). Since the flaA probe used shows a certain degree of cross-reactivity with the highly similar flaB gene (Nuijten et al., 1990), it is likely that the mRNA hybridizing to the flaA probe represents low levels of fla $B$ expression. In contrast, transcription of the flagellar motor gene $\operatorname{mot} B$ was not significantly affected by any of the mutations (Fig. 3b).

\section{Identification of the flhB promoter}

The transcription start point for $f l h B$ was determined by primer extension. This gave a weak but reproducible primer extension signal located $91 \mathrm{bp}$ upstream of the 


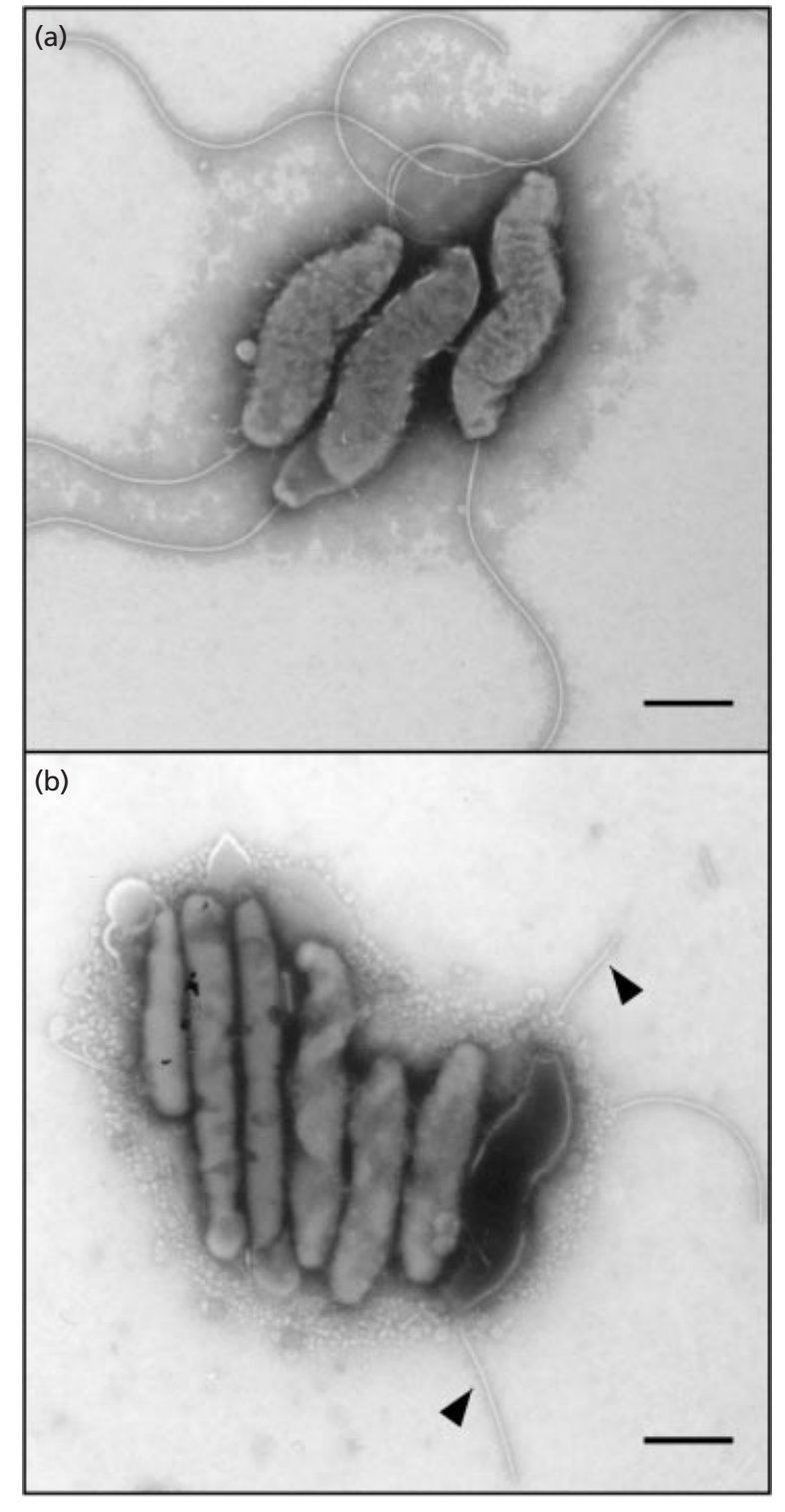

Fig. 2. Electron microscopy of $C$. jejuni 81116 and flhB mutant AV34. Cells were grown for $24 \mathrm{~h}$ and then negatively stained with potassium phosphotungstate $(\mathrm{pH} \mathrm{7 \cdot 0)}$. (a) $\mathrm{C}$. jejuni wildtype 81116. Most cells have a spirally curved morphology and full-length flagella. (b) C. jejuni flhB mutant AV34. Most cells are elongated, straight, and lack flagella. One cell exhibits a spirally curved morphology and truncated flagella (indicated by arrowheads). Bars, $0.5 \mu \mathrm{m}$.

flbB ATG codon (Fig. 4). Typical $\sigma^{70}$ or $\sigma^{28}$ promoter sequences were not obvious in the sequence directly upstream of the $f l h B$ transcription start point, but $39 \mathrm{bp}$ upstream of the transcription start point a typical $\sigma^{54}$ promoter sequence, GG-N ${ }_{10}-\mathrm{GC}$, was identified, as reported for the Campylobacter coli flaB and $f \lg E$ genes (Guerry et al., 1992; Kinsella et al., 1997). This promoter-like sequence, however, is too far upstream from the transcription start for it to be involved in this activity (Buck et al., 2000). The weak primer extension signal indicated that $f l b B$ is transcribed at a very low
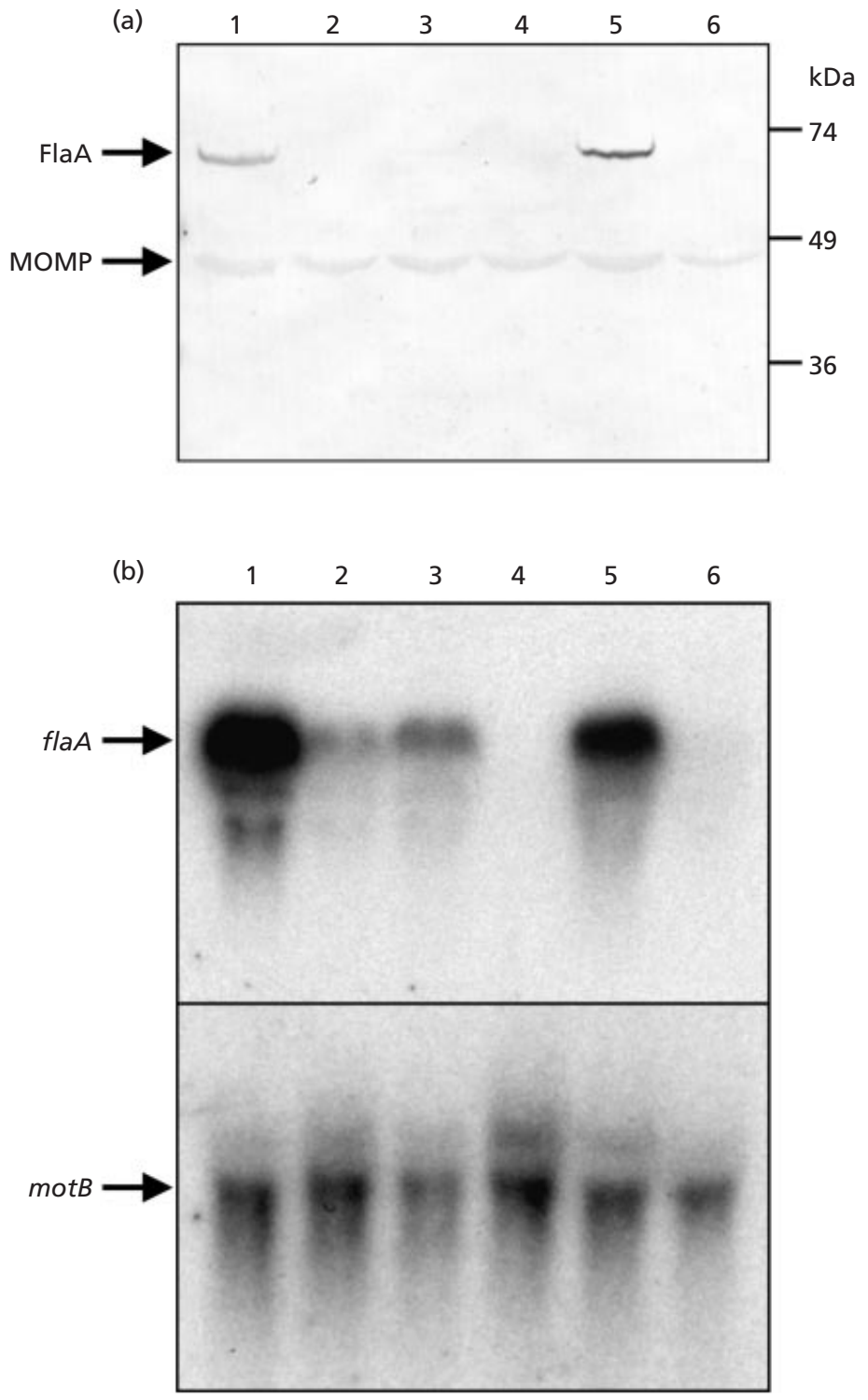

Fig. 3. Analysis of (a) Fla protein levels and (b) flaA and motB transcript levels in C. jejuni wild-type, flhB mutants AV33 and AV34, and flagellar mutants R2, R3 and R4. (a) Western immunoblot of C. jejuni whole-cell protein probed with the flagellum-specific monoclonal antibody P2D3. Marker sizes are given in $\mathrm{kDa}$ on the right, while on the left the FlaA protein is indicated. The monoclonal antibody or conjugate used displays a low level of cross-reactivity with the major outer-membrane protein (MOMP), as indicated on the left. (b) Northern hybridization of RNA isolated from $C$. jejuni cells in exponential growth phase, probed with flaA-specific (top panel) and motBspecific (lower panel) probes. Lanes: $1, C$. jejuni 81116; $2, C$. jejuni AV33; 3, C. jejuni AV34; 4, C. jejuni R2; 5, C. jejuni R3; 6, C. jejuni R4.

level, or that the transcript is unstable, and this was confirmed by the failure to detect an $f l h B$ transcript on Northern hybridization (not shown).

The pMW10-based lacZ reporter gene system (Wösten et al., 1998b) was used to identify the $f l h B$ promoter and 


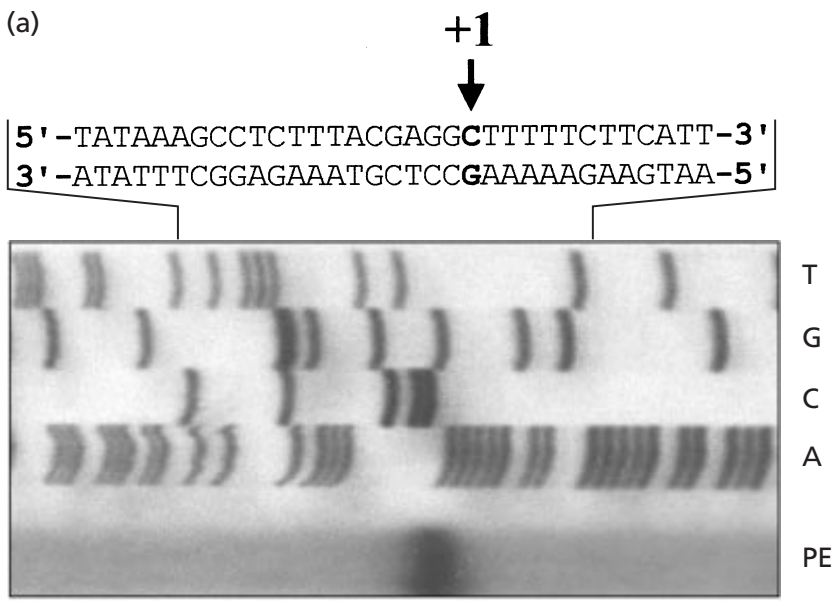

(b)

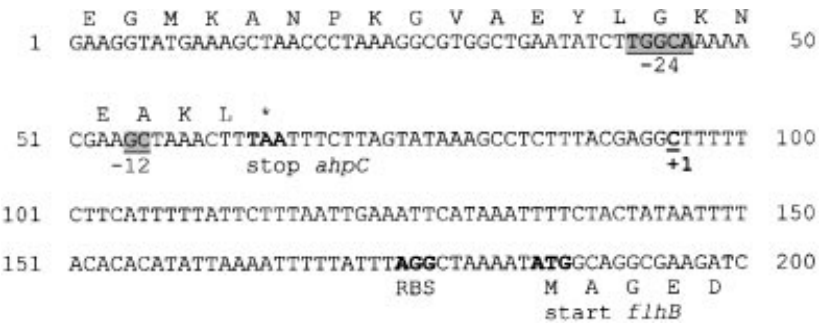

(c)

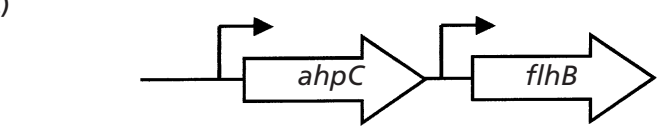

pAV197

pCM1

$\mathrm{pCM} 2$

$\mathrm{pCM} 3$

pCM4

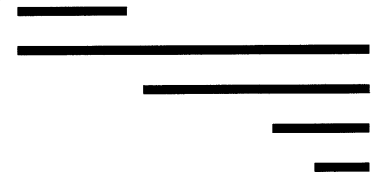

Fig. 4. Characterization of the $f / h B$ promoter region. (a) Primer extension analysis of $C$. jejuni mRNA with the flhB-specific oligonucleotide PE1. The lane marked PE contains the primer extension product, whereas the lanes marked A, C, G and $T$ contain a DNA sequencing reaction initiated with primer PE1 used for the primer extension reaction. (b) Sequence and annotation of the $a h p C-f / h B$ intergenic region. The transcription start site is indicated as +1 in bold typeface and is underlined. The stop codon of $a h p C$ and the start codon of flhB are shown in bold typeface; DNA sequences resembling the C. jejuni $\sigma^{54}$ consensus sequence are underlined, highlighted, and labelled as -12 and -24 . (c) Strategy for determining the promoter of $f / h B$. Overlapping fragments of the $C$. jejuni ahpC-flhB region were transcriptionally fused to the promoterless lacZ gene of pMW10 (Table 1).

to quantify transcription of $f l h B$, including any cotranscription with the upstream, iron-repressed $a h p C$ gene. Overlapping fragments were generated, containing either the direct upstream region of $f l b B$, or, in addition to this, the upstream $a h p C$ gene with and without its iron-regulated promoter (Fig. 4c, Table 1). The flaA promoter and the $a h p C$ promoter were used as positive controls (Table 1). Expression of the flbB: : lacZ fusions was only slightly, though reproducibly, higher than background levels, and was up to 100 -fold lower than activity from the $a b p C:$ : lac $Z$ fusion and 25 -fold lower than the flaA::lacZ fusion (Table 1). The inclusion of the $a h p C$ gene alone (pCM2) or the $a h p C$ gene and promoter (pCM1) upstream of the putative $f l h B$ promoter region did not significantly affect expression of the $f l b B:$ :lacZ fusion when compared with $\mathrm{pCM}$, indicating that transcriptional readthrough from the $a h p C$ promoter does not seem to play a role in transcription of $f l h B$. Conversely, removal of the sequences upstream of the transcription start point (pCM4) lowered $\beta$-galactosidase activity to background levels. Growth in iron-restricted media only affected $\beta$ galactosidase activity of the $a h p C:$ : lac Z fusion (Baillon et al., 1999), but not that of any of the flbB::lacZ or the flaA::lacZ fusions (Table 1), again confirming that there was no influence of the iron-regulated $a b p C$ promoter on $\mathrm{flhB}$ transcription.

\section{DISCUSSION}

Flagellar biogenesis has been extensively studied in $S$. enterica serovar Typhimurium and E. coli (Chilcott \& Hughes, 2000; Macnab, 1996), and it has been shown that the FlhB protein plays a central part therein. FlhB is involved in hook-length control and switch of export substrate as part of the flagellar export apparatus (Kutsukake et al., 1994; Kutsukake, 1997; Minamino et al., 1994; Minamino \& Macnab, 1999, 2000; Williams et al., 1996). However, experimental evidence as well as the availability of complete genome sequences from several bacteria have indicated that models developed for S. enterica serovar Typhimurium do not always correspond to those of other bacteria (O'Toole et al., 2000; Parkhill et al., 2000; Tomb et al., 1997). Here, we have initiated characterization of flagellar biogenesis in C. jejuni by studying the role and transcription of its $f l h B$ gene.

The FlhB protein seems to play a central role in flagellar biogenesis of $C$. jejuni, since the $f h B$ mutants used in this study did not assemble flagella. Similar observations were made with $H$. pylori flhB mutants, which were also non-motile and lacked flagella (Foynes et al., 1999). The flhB mutants of C. jejuni strain 81116 also generally exhibited a change in cell shape, from spiral cells with a relatively short aspect ratio to a straighter and apparently longer form. No explanation is apparent for this, but in polar flagellate bacteria where a new pole requires a new flagellum, there clearly must be coordination between flagellar insertion and cell division. Furthermore, it has been shown in the Enterobacteriaceae that cell-division events are affected by mutations in the $f l h D$ flagellar master-regulator, and it is possible that a cell-division gene(s), with implications for determination of aspects of cell shape, might be affected in aflagellate mutants (Chilcott \& Hughes, 2000; Prüß \& Matsumura, 1997).

Flagellin expression was significantly decreased in the $C$. jejuni $f h B$ mutant, and this was mediated at the transcriptional level. This repression of flagellin tran- 
scription and expression has also been described in mutants lacking other predicted components of the flagellar export apparatus in either H. pylori, C. coli or C. jejuni (Allan et al., 2000; Miller et al., 1993; O’Toole et al., 2000; Park et al., 2000). In contrast, mutants in the flagellar hook-encoding gene flgE in Helicobacter mustelae, H. pylori and C. coli are also non-motile and aflagellate, but express flagellin at normal levels so that it accumulates intracellularly (Kinsella et al., 1997; O'Toole et al., 1994, 2000). This suggests that full activation of flagellin genes in Campylobacter requires the proper assembly of the flagellar-specific export apparatus.

The levels of $f h B$ in C. jejuni were too low to allow detection in Northern hybridization experiments, and therefore we utilized reporter gene analysis to identify promoter sequences driving $f h B$ transcription. The reporter gene experiments confirmed that levels of $f l b B$ transcripts are very low, since the $\beta$-galactosidase activities of $f l b B:$ : lac $Z$ fusions were only slightly higher than background values. Transcription of $f l h B$ is not affected by the presence or absence of the upstream $a h p C$ gene and promoter, thus demonstrating that the $f h B$ gene is transcribed at a low level from its own promoter, and indicating there is an (as yet unidentified) transcriptional stop between the $f h B$ and $a h p C$ genes. Taken together, these results demonstrate that $f l b B$ is transcribed at a low level, that the $f h B$ promoter is located in the $a h p C-f l h B$ intergenic region, that transcription starts at the experimentally determined transcription start point, and that it is independent of the iron-repressed promoter of the upstream-located $a p h C$ gene. In conclusion, the $f l b B$ gene is essential for flagellar biogenesis in C. jejuni, and is likely to function as a component of the flagellar export apparatus.

\section{ACKNOWLEDGEMENTS}

We thank Ben van der Zeijst for C. jejuni mutants R2, R3 and R4, and Marc Wösten for plasmid pMW10. This work was supported by grants from the School of Biosciences, University of Birmingham, to C.M., from the Wellcome Trust, to J.M.K., and from the Nederlandse Organizatie voor Wetenschappelijk Onderzoek (NWO 901-14-206), to A.H.M.v.V.

\section{REFERENCES}

Allan, E., Dorrell, N., Foynes, S., Anyim, M. \& Wren, B. W. (2000). Mutational analysis of genes encoding the early flagellar components of Helicobacter pylori: evidence for transcriptional regulation of flagellin A biosynthesis. J Bacteriol 182, 5274-5277.

Baillon, M.-L. A., van Vliet, A. H. M., Ketley, J. M., Constantinidou, C. \& Penn, C.W. (1999). An iron-regulated alkyl hydroperoxide reductase $(\mathrm{AhpC})$ confers aerotolerance and oxidative stress resistance to the microaerophilic pathogen Campylobacter jejuni. J Bacteriol 181, 4798-4804.

Buck, M., Gallegos, M. T., Studholme, D. J., Guo, Y. \& Gralla, J. D. (2000). The bacterial enhancer-dependent $\sigma^{54}\left(\sigma^{\mathrm{N}}\right)$ transcription factor. J Bacteriol 182, 4129-4136.

Chilcott, G. S. \& Hughes, K. T. (2000). Coupling of flagellar gene expression to flagellar assembly in Salmonella enterica serovar typhimurium and Escherichia coli. Microbiol Mol Biol Rev 64, 694-708.

Colegio, O. R., Griffin, T. J., Grindley, N. D. \& Galan, J. E. (2001). In vitro transposition system for efficient generation of random mutants of Campylobacter jejuni. J Bacteriol 183, 2384-2388.

Constantinidou, C., Hellyer, T. J., Richardson, P. T. \& Penn, C. W. (1996). Cross-reactivities and strain-specificity of monoclonal antibodies to Campylobacter jejuni and Helicobacter pylori flagellins. In Campylobacters, Helicobacters and Related Organisms, pp. 663-666. Edited by D. G. Newell, J. M. Ketley \& R. A. Feldman. New York: Plenum Press.

Foynes, S., Dorrell, N., Ward, S. J., Zhang, Z. W., McColm, A. A., Farthing, M. J. \& Wren, B. W. (1999). Functional analysis of the roles of FliQ and FlhB in flagellar expression in Helicobacter pylori. FEMS Microbiol Lett 174, 33-39.

Guerry, P., Alm, R. A., Power, M. E. \& Trust, T. J. (1992). Molecular and structural analysis of Campylobacter flagellin. In Campylobacter jejuni: Current Status and Future Trends, pp. 267-281. Edited by I. Nachamkin, M. J. Blaser \& L. S. Tompkins. Washington, DC: American Society for Microbiology.

Hendrixson, D. R., Akerley, B. J. \& Dirita, V. J. (2001). Transposon mutagenesis of Campylobacter jejuni identifies a bipartite energy taxis system required for motility. Mol Microbiol 40, 214-224.

Jagannathan, A., Constantinidou, C. \& Penn, C. W. (2001). Roles of $r p o N$, fliA, and flgR in expression of flagella in Campylobacter jejuni. J Bacteriol 183, 2937-2942.

Kinsella, N., Guerry, P., Cooney, J. \& Trust, T. J. (1997). The flgE gene of Campylobacter coli is under the control of the alternative sigma factor $\sigma^{54}$. J Bacteriol 179, 4647-4653.

Kutsukake, K. (1997). Hook-length control of the exportswitching machinery involves a double-locked gate in Salmonella typhimurium flagellar morphogenesis. J Bacteriol 179, 1268-1273.

Kutsukake, K., Minamino, T. \& Yokoseki, T. (1994). Isolation and characterization of FliK-independent flagellation mutants from Salmonella typhimurium. J Bacteriol 176, 7625-7629.

Macnab, R. M. (1996). Flagella and motility. In Escherichia coli and Salmonella: Cellular and Molecular Biology, pp. 123-145. Edited by F. C. Neidhardt. Washington, DC: ASM Press.

Miller, S., Pesci, E. C. \& Pickett, C. L. (1993). A Campylobacter jejuni homolog of the LcrD/FlbF family of proteins is necessary for flagellar biogenesis. Infect Immun 61, 2930-2936.

Minamino, T. \& Macnab, R. M. (1999). Components of the Salmonella flagellar export apparatus and classification of export substrates. J Bacteriol 181, 1388-1394.

Minamino, T. \& Macnab, R. M. (2000). Domain structure of Salmonella FlhB, a flagellar export component responsible for substrate specificity switching. J Bacteriol 182, 4906-4914.

Minamino, T., lino, T. \& Kutsukake, K. (1994). Molecular characterization of the Salmonella typhimurium flhB operon and its protein products. J Bacteriol 176, 7630-7637.

Nachamkin, I., Yang, X. H. \& Stern, N. J. (1993). Role of Campylobacter jejuni flagella as colonization factors for threeday-old chicks: analysis with flagellar mutants. Appl Environ Microbiol 59, 1269-1273.

Nuijten, P. J. M., van Asten, A. J. A. M., Gaastra, W. \& van der Zeijst, B. A. M. (1990). Structural and functional analysis of two Campylobacter jejuni flagellin genes. J Biol Chem 265, 17798-17804.

Nuijten, P. J., van den Berg, A. J. G., Formentini, I., van der Zeijst, B. A. M. \& Jacobs, A. A. C. (2000). DNA rearrangements in the flagellin locus of an flaA mutant of Campylobacter jejuni during colonization of chicken ceca. Infect Immun 68, 7137-7140. 
Oelmuller, U., Kruger, N., Steinbuchel, A. \& Friedrich, C. (1990). Isolation of prokaryotic RNA and detection of specific mRNA with biotinylated probes. J Microbiol Methods 11, 73-81.

O’Toole, P. W., Kostrzynska, M. \& Trust, T. J. (1994). Non-motile mutants of Helicobacter pylori and Helicobacter mustelae defective in flagellar hook production. Mol Microbiol 14, 691-703.

O'Toole, P. W., Lane, M. C. \& Porwollik, S. (2000). Helicobacter pylori motility. Microbes Infect 2, 1207-1214.

Park, S. F., Purdy, D. \& Leach, S. (2000). Localized reversible frameshift mutation in the $f h A$ gene confers phase variability to flagellin gene expression in Campylobacter coli. J Bacteriol 182, 207-210.

Parkhill, J., Wren, B. W., Mungall, K. \& 18 other authors (2000). The genome sequence of the food-borne pathogen Campylobacter jejuni reveals hypervariable sequences. Nature 403, 665-668.

Prüß, B. M. \& Matsumura, P. (1997). Cell cycle regulation of flagellar genes. J Bacteriol 179, 5602-5604.

Sambrook, J., Fritsch, E. F. \& Maniatis, T. (1989). Molecular Cloning: a Laboratory Manual, 2nd edn. Cold Spring Harbor, New York: Cold Spring Harbor Laboratory.

Spohn, G. \& Scarlato, V. (1999). Motility of Helicobacter pylori is coordinately regulated by the transcriptional activator FlgR, an NtrC homolog. J Bacteriol 181, 593-599.

Szymanski, C. M., King, M., Haardt, M. \& Armstrong, G. D. (1995). Campylobacter jejuni motility and invasion of Caco-2 cells. Infect Immun 63, 4295-4300.

Tomb, J. F., White, O., Kerlavage, A. R. \& 39 other authors (1997). The complete genome sequence of the gastric pathogen Helicobacter pylori. Nature 388, 539-547.

van Vliet, A. H. M. \& Ketley, J. M. (2001). Pathogenesis of enteric Campylobacter infection. J Appl Microbiol 90, 45S-56S. van Vliet, A. H. M., Wood, A. C., Henderson, J., Wooldridge, K. G. \& Ketley, J. M. (1998a). Genetic manipulation of enteric Campylobacter species. Methods Microbiol 27, 407-419.

van Vliet, A. H. M., Wooldridge, K. G. \& Ketley, J. M. (1998b). Iron-responsive gene regulation in a Campylobacter jejuni fur mutant. J Bacteriol 180, 5291-5298.

van Vliet, A. H. M., Rock, J. D., Madeleine, L. N. \& Ketley, J. M. (2000). The iron-responsive regulator Fur of Campylobacter jejuni is expressed from two separate promoters. FEMS Microbiol Lett 188, 115-118.

Wassenaar, T. M., Bleumink-Pluym, N. M. C. \& van der Zeijst, B. A. M. (1991). Inactivation of Campylobacter jejuni flagellin genes by homologous recombination demonstrates that flaA but not $f l a B$ is required for invasion. EMBO J 10, 2055-2061.

Wassenaar, T. M., van der Zeijst, B. A. M., Ayling, R. \& Newell, D. G. (1993). Colonization of chicks by motility mutants of Campylobacter jejuni demonstrates the importance of flagellin A expression. J Gen Microbiol 139, 1171-1175.

Williams, A. W., Yamaguchi, S., Togashi, F., Aizawa, S. l., Kawagishi, I. \& Macnab, R. M. (1996). Mutations in $f l K$ and $f l h B$ affecting flagellar hook and filament assembly in Salmonella typhimurium. J Bacteriol 178, 2960-2970.

Wösten, M. M. S. M., Boeve, M., Gaastra, W. \& van der Zeijst, B. A. M. (1998a). Cloning and characterization of the gene encoding the primary $\sigma$-factor of Campylobacter jejuni. FEMS Microbiol Lett 162, 97-103.

Wösten, M. M. S. M., Boeve, M., Koot, M. G., van Nuenen, A. C. \& van der Zeijst, B. A. M. (1998b). Identification of Campylobacter jejuni promoter sequences. J Bacteriol 180, 594-599.

Received 7 January 2002; accepted 15 February 2002. 